\title{
Making a sustainable network-community for refugees from the Fukushima nuclear plant disaster in a stable historic castle town and region
}

\author{
Shigeru Satoh \\ Department of Architecture, Urban Design and Planning, Waseda University. Japan \\ E-mail: gerusato@waseda.jp
}

\begin{abstract}
After the Fukushima nuclear power plant accident disaster, all of the residents in the area contaminated by radioactivity and all public facilities were evacuated to surrounding regions or more remote cities on the direction of the central government. As a result, temporary housing estates for the refugees are scattered, and aged refugees still remain on these estates six years after the disaster. The town of Namie had the largest number of people who were ordered to evacuate in the evacuated area. The city of Nihonmatsu, adjacent to the contaminated area, is a typical Japanese castle town, and accepted many Namie refugees, offering temporary housing, and housing the town office, schools, hospitals, industrial sites, etc. The Fukushima Namie Recovery Project team, organized by the NPO Shinmachi-Namie and Waseda University, proposed a Network-community connecting several refugee housing estates, evacuated public facilities and other core city services. These need to be connected and their community reintegrated, in practice facilitating the "support system for the network community". This vision of a Network-community would be adapted to the historically stable region, which includes various dispersed, aged and isolated communities. Nihonmatsu, as the Castle Town of the Nakadori region of Fukushima Prefecture, is noteworthy for its historical urban areas, old streets, lots of unoccupied housing etc. That is, it is very hard to get the people of Nihonmatsu to think optimistically about shelter for Namie evacuees. Nevertheless, areas of the Nakadori region including Nihonmatsu may cooperate with the Namie evacuees and reinvigorate the ruined coastline by means of the "Network Community" - a network encompassing various historical traditions that still exist today as regional assets; thus, the vision for the future of Fukushima is one of hope.
\end{abstract}

Keywords: Network community, Castle town region, Refugees from Fukushima nuclear power plant accident disaster

\section{Introduction}

Due to the disastrous incident that occurred in the Fukushima Daiichi Nuclear Power Plant (operated by TEPCO), the entire population of the town of Namie were compelled to leave their livelihoods and evacuate to other parts of Japan. Since this disaster, both the Waseda Institute of Urban and Regional Studies and the Satoh Laboratory of Waseda University have devoted themselves to the rehabilitation of the devastated areas. Both groups received a request from the Machizukuri Corporation NPO Shin-machi Namie (abbreviated below to: Shin-machi Namie), and since the autumn of 2011, the Waseda Group have endeavoured to support the Fukushima victims through activities aimed at community rehabilitation. The fundamental stance of our research then is close cooperation with the city plan of the Namie-machi administration, and the 
promotion of the Rehabilitation Machizukuri project. To this end, a mutual agreement for three-way research cooperation was reached between the Namie Town government, the Non-Profit Organization "Shin-machi Namie" and Waseda University, so that the Machizukuri project may proceed smoothly. At the beginning of 2012, the Waseda research group proposed a basic schema for a circulatory process for the restoration of the Namie community over a period of thirty or forty years. (Fig. 1)

March 2017 marked six years since the disaster, and in April of this year the evacuation order was cancelled in the central section of Namie town, although the entire population of the town has evacuated, sought refuge elsewhere, and settled down in new communities built around the outskirts of Namie or in a number of host cities. (Table 1)

For the time being, before they are able to return to Namie-town, the spiritual and material safety and stability of the private lives of the refugees must be ensured. The task remains of upgrading infrastructure and planning new public housing in the host cities of Fukushima Prefecture, and the evacuees must carry on rebuilding their lives and moving forward to a fresh start; yet, these scattered evacuee communities should not be isolated. Close to each community should be constructed public facilities, familiar grocery stores or cafés for social interaction so that the scattered communities can interact and are not cut off from each other. Every "Namie outer community in a host city" built with familiar public facilities close by may not only interact with other communities but also inherit the culture and heritage of Namie. In order to beef up these "neighbouring communities," they need to be linked by means of an information system and a means of transit; and therefore the concept of the "Network Community (Fig.
2)" was put forward.

Taking the concept of the "Network Community" as its basis, this paper describes the "emerging multi-layered urban region in the host city region which accepted refugees from the contaminated coastal area, forming a network-community for refugees, centred on a historically stable castle town and its surroundings".

The network-community includes the "outer communities" formed by refugees and the "inner communities" in Namie town as base via which refugees may return to their home town, and these outer and inner communities are linked by a network of transit and information systems.

\section{Research Question regarding the New Network-community and the Historic Region}

The research question of this paper is how to build a network-community connecting the "Namie outer communities in host cities", and how to revitalize the city region by means of a network-community formed in the historically stable and declining castle town region.

One of the host cities accepting evacuees from the disaster area, the City of Nihonmatsu is a typical Japanese castle town. Nihonmatsu Castle is located on hilly land in the centre of a basin, and the castle town developed along the Oshu Highway axis that runs east to west. The town was constructed by Niwa Mitsushige, beginning in 1643. The Kasumigajo castle was constructed on a hill to the northwest of the town, and the samurai area was laid out below the castle. The castle town in its entirety was built with a sophisticated landscape design early in the 17th century, surrounded by and in harmony with nature, composed of mountains

\section{Number of refugees}

Total

within Fukushima Pref. outside of Fukushima Pref.
From Namie Town (as of 31th/Dec. /2016)

20,833

14,470

6,363
From Fukushima Pref. overall (as of $20^{\text {th }} / \mathrm{Feb} . / 2017$ )

Table1 


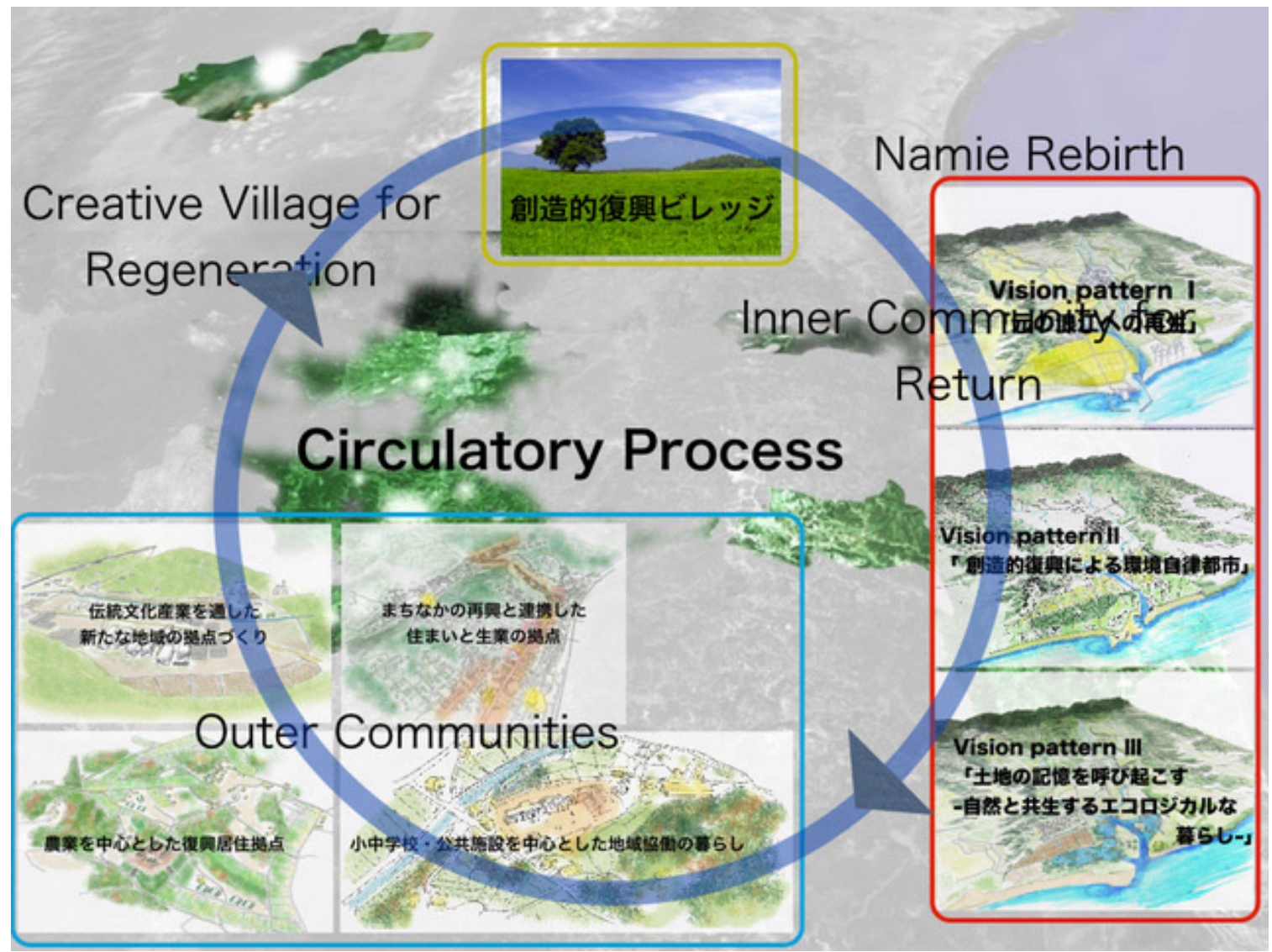

Figure 1. (Hypothetical Vision for Rebuilding the Namie Community)

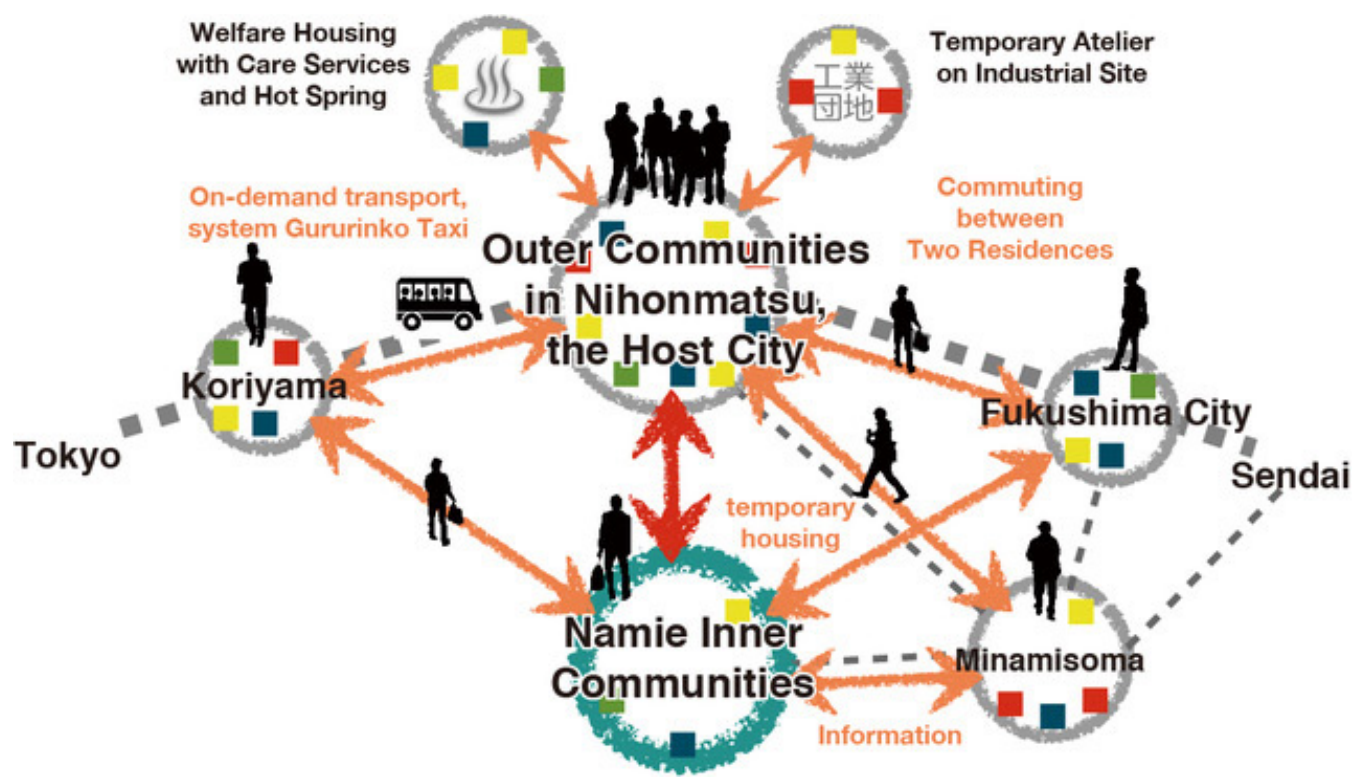

Figure 2. (Image of Network-Community for Rebirth) 
clothed in forests and an abundant water supply, symbolizing a sacred place. Using the natural environment as its foundation, urban planning is done organically, incorporating Nature. Various important places and views are connected and linked in the historic city and its surrounding areas. (Fig. 3)

In the Modern Age, since the late 19th century, the Nihonmatsu city region grew as a regional centre. Modern infrastructure was built over the historic urban form starting in the late 19th century, and urban sprawl was evident.

Since the 1980s, Nihonmatsu city centre and its surrounding areas have been declining, losing population and commercial activity a common phenomenon in provincial urban areas throughout Japan.

After the disaster on the 11th March 2011, the schools and public facilities of Namie Town were removed from the original town area and scattered throughout the Nihonmatsu city region together with some temporary housing estates. "Outer communities," which were formed from temporary housing and other public facilities just after the disaster, need to be transformed in various ways into stable communities for the future lives of the refugees, through the construction of public and other housing, community and health care facilities. The laying over this region of a network-community of the refugees' outer communities will cause a new active energy and diversified culture to emerge. The laying of a network community over the stable and rather declining region could energise and regenerate the region. In order to avoid the isolation of each outer community, the communities should be linked by an on-demand transit system managed by a non-profit organization, and linked by an online social network system.

A collaborative planning process implemented between Nihonmatsu City and Namie Town, both at the citizen level and at the local government level, would have the effect of revitalising the region through the overlaying of the network-community. On this basis, if the Namie evacuees and the citizenry of Nihonmatsu could work together, a new model of community recovery is possible.
Those developed, or mature, regions may appear to be stable, but behind their outward appearance those regions themselves can be dull and inactive. In addition, the evacuee communities have had no alternative but to evacuate from their deep cultural roots to other regions, so conflict between the host communities and the evacuee communities does occur.

Taking as its basis the concept of the "Network Community," this paper presents four stages describing the particulars and details of the actions and methods employed, which are still being developed by our research team members. The aim is to make the town people aware of the meaning of "action research" by bringing up the process in thorough discussion of the process of action, and by expanding cooperation between the numerous subjective groups; and in this way we may expect the townspeople to see their regions energized and their communities revived.

This research began in Stage One by matching the project developed by the Japan Scientific and Technology Agency (JST) and designed to suit multiple dwellings for evacuees who favour the scattered type of community; this paper concerns itself here with how the Network Community is shaped.

\section{Sharing of the Rehabilitation Scenario Stage 0: September $2011 \sim$ September 2012}

Having been asked to help the project of "Shinmachi Namie," the Waseda Institute of Urban and Regional Studies and the Satoh Laboratory of Waseda University began to work on this in September 2011, setting up collaboration and team participation as the premise for the study and promotion of the assumed vision for the long-term rehabilitation of Namie. Here we set out the process for Stage Zero, in which the scenario of a network community and the vision of rehabilitation for tomorrow was prepared and shared with the people of the town.

The nuclear power plant accident was both a turning point and yet an opportunity as well. Many of the town folk wish to return to Namie and others don't; yet the townspeople as a 


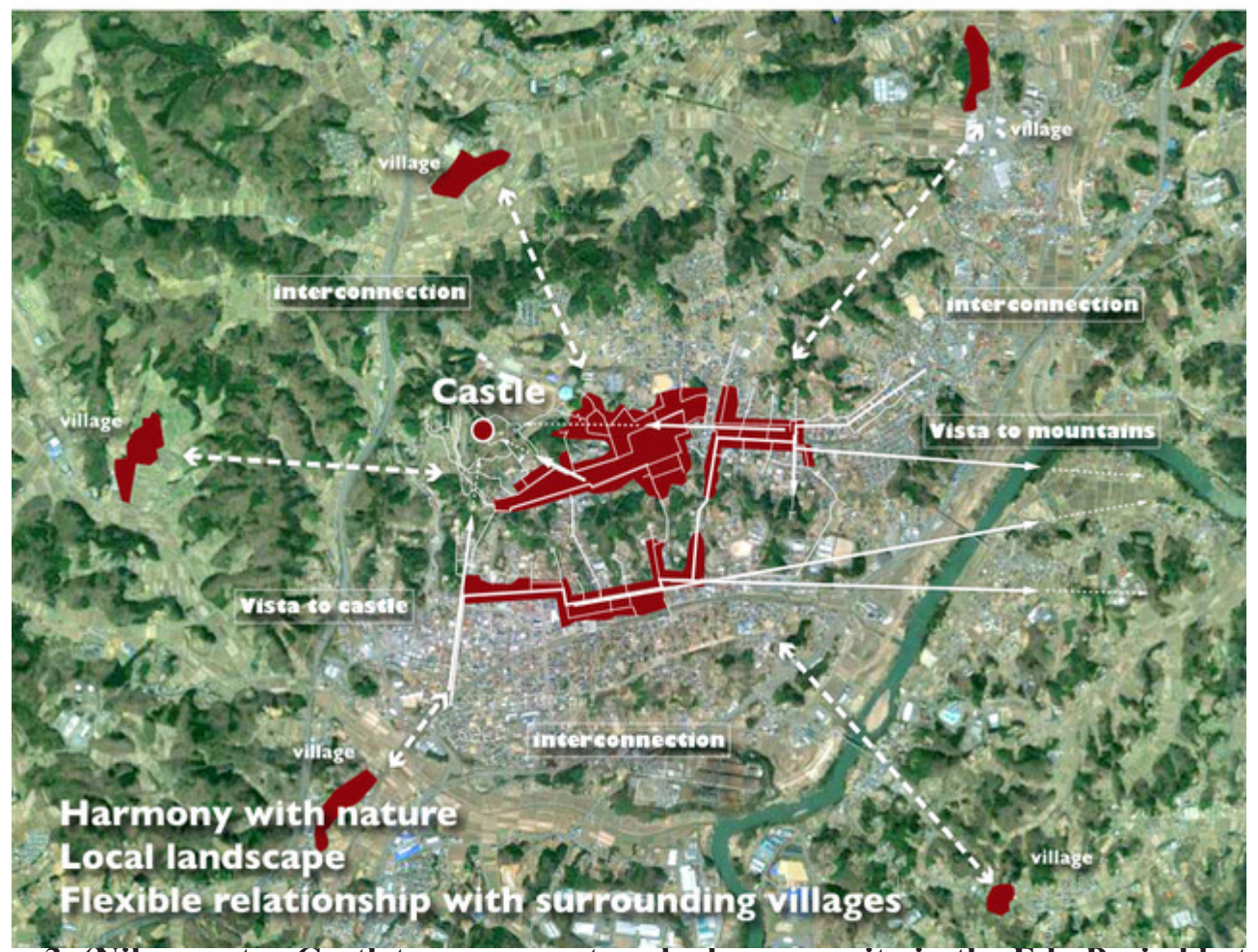

Figure 3. (Nihonmatsu Castletown as a networked community in the Edo Period between the $17^{\text {th }}$ and $20^{\text {th }}$ centuries)

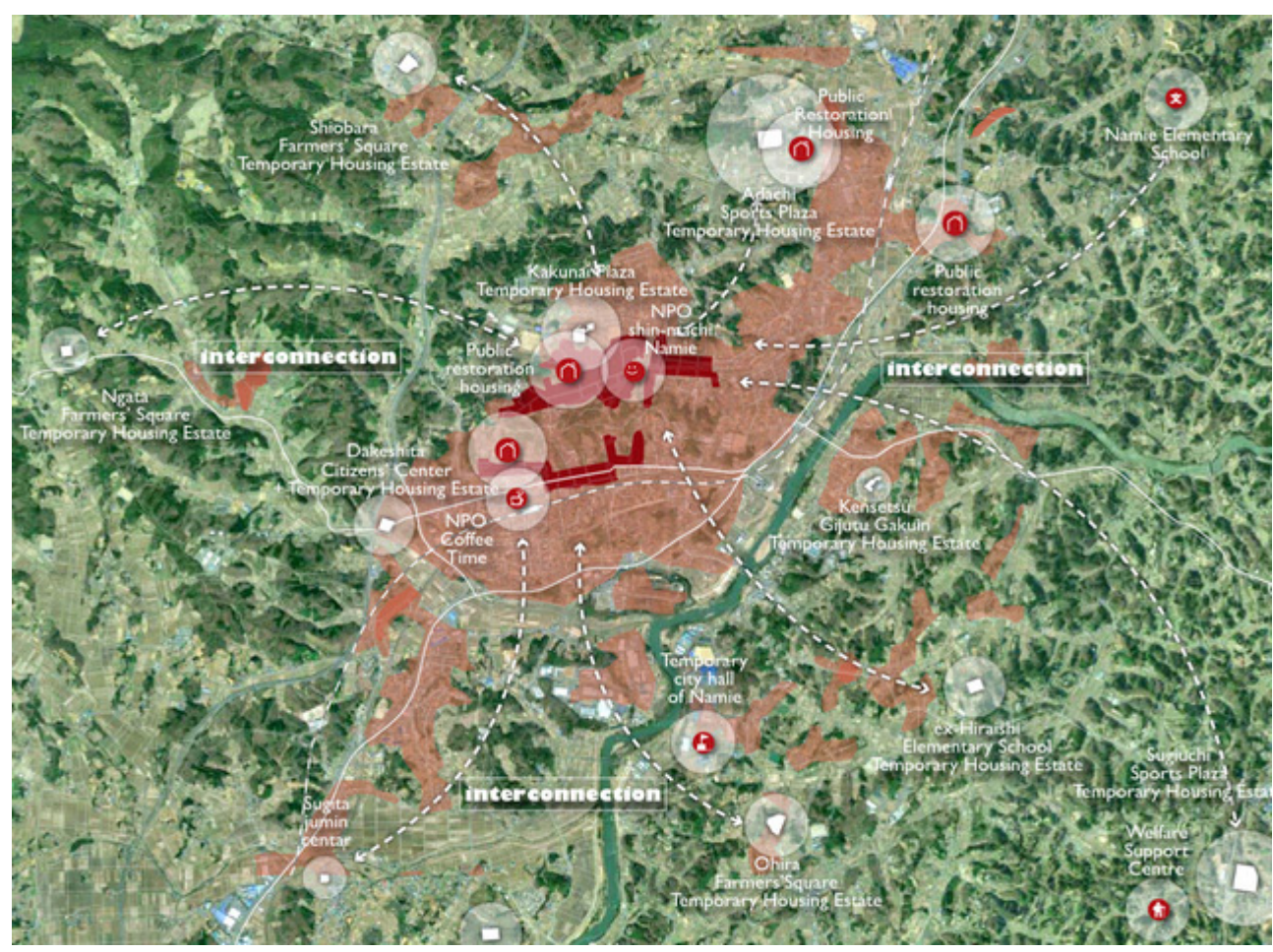

Figure 4. (Interconnection between outer communities, various layers and elements of the network system) 
whole need a vision to keep them together and maintain a unified community.

Below are described three types of community cooperation designed with the concept of linkage (see Chart 2), to pave the way for reconstruction.

(1) The Namie Inner Communities (the communities to be rebuilt within Namie)

The process for the return to Namie-machi still remains uncertain; the $R \& D$ group assumed three scenarios relating to the future of Namie. In the first scenario, the majority of the people of Namie, around $60 \%-80 \%$, would return and be eager to see the regeneration of their town as it was before, and the revival of their communities. In the second scenario, many young people would feel hesitant about going home, but roughly half - about $40 \%$ $60 \%$ - of them would like to make Namie "an autonomous city regenerated by creative reconstruction." And in the third scenario it is assumed that only $20 \%-40 \%$ would return; they would recall the memory of Namie and live ecologically in harmony with nature.

(2) Little Namie (Namie outer communities) The communities built in host cities as rehabilitation housing complexes must be able to meet the diverse needs of the evacuees. A network system, in particular, is needed to keep the scattered communities in touch with each other. Collaboration may also help revitalise the host cities.

(3) Villages of Creative Rehabilitation

Leaving Fukushima to search for new communities nearby or elsewhere in the Japanese islands, these evacuees would surely be eager for a community where they can have a stable life together. Making the most of the untapped resources of the land, they can lead a gentle life, raising their children, farming, raising livestock and enjoying social welfare, free from the radioactive contamination.

The mechanism to support the Network Community system $\sim$ Creating a rough consensus Stage 1: October $2012 \sim$ March 2013

Since October 2012, the activities of Stage Zero have been developed and implemented as a JST R\&D project. The Satoh Laboratory of Urban Planning, Waseda (the Satoh Group), the Asano Mitsuyuki Laboratory of Transportation Planning (the Asano Group), and the Andō Kiyoshi Laboratory of Social Psychology, Tōyō University (the Andō Group) took this opportunity to establish a new JST research group.

Here, we describe the process of Stage One in which a specific spatial image of the Network Community, the mechanism to support it and the scheme to put it into practice were studied.

\section{Community Spatial Image and Public Transport System}

Motivated by the idea of the Network Community developed and shared in Stage Zero, the Waseda team worked out three types of community design with specific spatial planning; two of these are Namie outer communities formed in host cities, and the third type was designed within Namie itself.

Type (1) is the "Outer Community within in the Host City," planned in cooperation with the host city to build public housing and establish bases for commercial and welfare services.

Type (2) is the "Outer Community outside the Host City," established close to the temporary housing on the outskirts of the host city, with the aim of sustaining the Namie evacuee communities that developed in the temporary housing.

Type (3) is the "Namie Inner Communities," meaning the communities to be rebuilt within Namie in the future as bases to which the evacuees could return, planned with an eye to promoting the full-scale return to Namie in the long term.

When thinking about the public transport system, the Asano Group considered the possibility of their New Gururinko transportation system being accepted, based on the image of the on-demand Namie Gururinko taxi system, which had been widely used by the townsfolk prior to the Great Earthquake and Tsunami Disaster of 2011. From this starting point, the Asano Group designed three transportation systems; the Nakayoshi towntaxi for daily activities like shopping or hospital visits, the Mirai town-taxi for temporary returns to Namie, and the Enjoy town-taxi for 
travel to recreational facilities like theatres, hot springs and hotels, and transit between homes and various public locations.

Based on the October Organisers' Meeting and the workshops held in November 2012, the models made for Machizukuri and related systems were amended and modified; and on 23-24 November the traditional Toka-ichi Festival (the most significant traditional annual event in Namie, held ever since the Meiji Era) was held in Nihonmatsu and opened to the people of Nihonmatsu for participation and creative suggestions.

Namie Declaration 1303: the Process for full-scale project implementation

Following the planning of the three types of communities, the research groups gave serious consideration to the project schemes to implement the designed projects, seeking to energise the evacuee communities.

The Satoh Group and the Asano Group, working in cooperation with the researchers and consultants from the Waseda Institute of Urban and Regional Studies, proposed several business models and the staff capable of providing the necessary cooperation. After two Organisers' meetings, most organizers had an understanding of what projects they were able to participate in, and their individual role.

Take the town of Kori-machi to begin with; this town, located in the northern part of Fukushima Prefecture, provided land on which to build a temporary housing complex for evacuees, almost all of whom are from Namie. The land is right next to the town, and plans went ahead to build a municipal rehabilitation public housing complex and private housing for sale. Thus, the abovementioned "Outer community outside the host city" is working towards the rehabilitation of Namie; meanwhile, the Chairman of the local government, an organiser of the Fukko-juku project, began a survey of the people living in temporary housing regarding their intentions to live in this outer community outside the host city.

The NPO Corporation Jin (Jin) had been involved in the social welfare of Namie before the earthquake disaster of 2011, and since the disaster, Jin has run Support Centres in the contemporary housing complexes, and has considered the possibility of running the New Gururinko transportation system out of its Support Centre in Sugiuchi District, Nihonmatsu.

The Namie Association of Commerce and Industry has begun working on commercial activities in cooperation with the commercial areas of Nihonmatsu City to where many Namie people evacuated, and some members have started to emerge who have firmly resolved to boost local commerce and industry by creating a commercial base for the "outer community within the host city".

Through this process, the six Projects aimed at bringing about the great vision of dreams and hope shared in Stage Zero were put into practice and the Namie Declaration 1303 was officially issued on March 2013, and received the approval of many at the Namie Rehabilitation Symposium, held in the same month.

\section{Building a foundation for the implementation of Rehabilitation Machizukuri in the refuge areas Stage 2: April $2013 \sim$ March 2014}

In Stage One, the structure to support the image of the Network Community was shared with the local government of the host city, and with the forming of a system of mutual collaboration the foundation was in place to build the Namie Outer Communities in Host Cities in preparation for the transfer of these Outer Communities back to Namie.

The aim here is to advocate "Machizukuri for Cooperative Rehabilitation," and in order to put this into practice, the rules and structure of a cooperative network must be prepared as the foundation on which this Machizukuri for Cooperative Rehabilitation can be built. This is the process of Stage Two.

\section{A study: the Business Scheme to start the Cooperative Rehabilitation}

The first step to Nihonmatsu-Namie Cooperative Rehabilitation was taken in the central area of Nihonmatsu City where the temporary housing constructions and many Namie evacuees are concentrated. A series of 
meetings and discussions was held focused on the issue of how to energise the town of Nihonmatsu whilst building the Namie Outer Community in the Host City through the sharing by the people of Nihonmatsu and the Namie evacuees of the town's vacant land, unoccupied housing, and the commercial areas and historical resources of the castle town. The Satoh Group added to these discussions, from its surveys of vacant land and unoccupied housing, several proposals and amendments to the Namie Declaration 1303. All this, then, was examined carefully by the businessmen, tradesmen and professionals in various fields from both Namie and Nihonmatsu, and discussions began regarding a scheme to put these amendments into practice. Organisational issues regarding land acquisition and the procurement of funding to put the scheme into effect were shared, and it became clear that for the process of Cooperative Rehabilitation to go ahead it would be necessary to request the national government, the prefectural government and Namie to facilitate systematic land use.

\section{Preparation of a structure to request a system to promote Cooperative Rehabilitation}

Thus, in order to act in accordance with the consensus of the evacuees with regard to this request, the Satoh Group proposed the establishment of the Machizukuri Committee headed by the Chairman of the temporary housing residents' association, and in September 2013 a meeting of the representatives of the temporary housing residents' association was held.

Moreover, since the Machizukuri for Namie Cooperative Rehabilitation must be seen as a model for recovery for all communities struck by the nuclear power plant disaster, with the cooperation of the Fukushima Cooperative Rehabilitation (Co-Rehabi), which has built a network of victims from every part of the nuclear disaster area and their supporters, a Machizukuri forum was held. At this forum, the "Vision for the Cooperative Rehabilitation of Fukushima" was adopted by the disasterhit communities and host communities of Fukushima as a body, and thus Cooperative Rehabilitation was started. (see Fig. 6)
Later, the Namie Machizukuri Council for Rehabilitation (the Council) was founded, following the holding of two preparatory meetings at which official requests were made and processed forward. This led to the Namie Declaration 1405, and in May 2014 the Council was officially established. In addition, a petition endorsed with over 1,100 signatures was handed in to the Mayor of Namie Town.

\section{Beginning the experiment in earnest Stage 3: April $2014 \sim$}

Finally, we come to Stage Three, in which practical experiments based on the activities carried out so far would be carried out in earnest.

To begin with, the Council shares information using the Namie Information Network and holds a regular monthly meeting. In addition, a network system is planned whereby a tablet terminal will be distributed to each of the more than 10,000 Namie households before the end of the 2014 fiscal year, and in cooperation with Code for Japan an app is being developed to maintain the bond between the townspeople. It is expected that this system will be used and updated, boosting the easy and timely sharing of information via SNS.

Based on the results of the New Gururinko taxi experiment in Stage Two, Jin, an NPO Corporation involved in this kind of social welfare experiment, has started full-scale practical tests - the Nakayoshi-taxi service in the Sugiuchi temporary housing area, and the Enjoy taxi service in the Adachi temporary housing area, etc. In addition, the monitoring system Ogenki Call System, developed by Professor A. Ogawa of Iwate City Univ., and using the telephones being installed in each area will surely serve a vital role in supporting the daily lives of the people of Namie. (Fig.2) Further, in Ishikura District, land adjacent to the Adachi temporary housing complex has been reserved for the construction of prefectural disaster recovery public housing. The attached facilities will include the clinics and assembly halls evacuated from Namie and already established in the Adachi temporary housing complex. This plan is by and large 
similar to the "Outer community outside the host city" of Stage One. In the case of Ishikura, the Waseda team has studied the possibility of town development incorporating the outskirts working on the premise that two hundred units of middle-class public housing will be built compliant with Fukushima standards. Working with the residents of the Adachi temporary housing complex, the Satoh Group has studied this perspective through a series of workshop meetings with the residents of the Adachi complex, using models. (Fig.5)
In this way, Stage Three is still on-going and the full-scale practical experiments are being carried out on the basis of the shared vision and the system established in Stage Two. This scheme could be expanded to all areas of Fukushima Prefecture where the many negative impacts of the nuclear plant accident damaged the local economy and society, in order to revitalise this area. (Fig. 6)
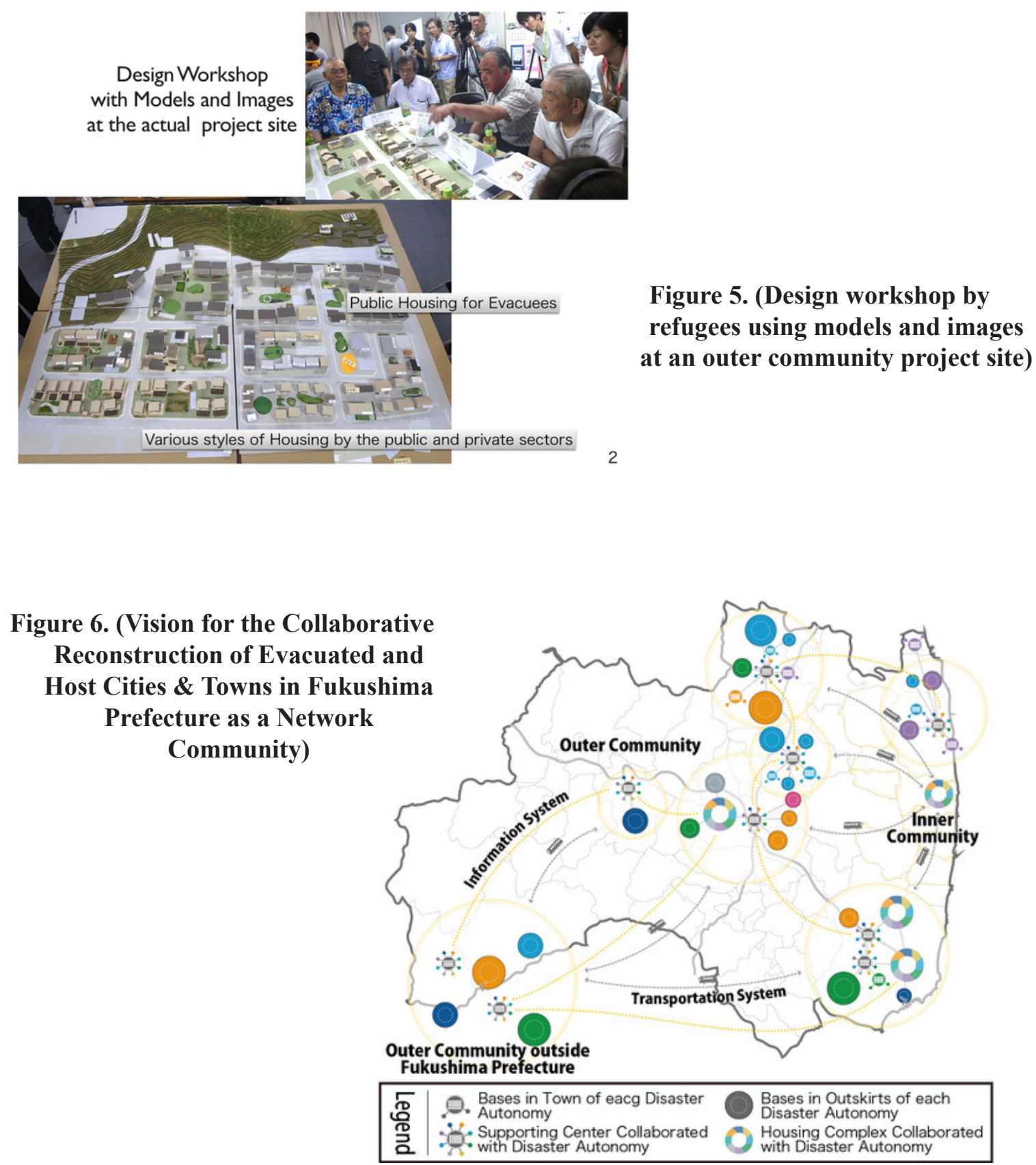


\section{Conclusion}

The 21 st century faces a complicated situation, both locally and globally. As we see in Europe today, some local communities are becoming unstable and swinging between the developed, mature Europe and those unstable, changing regions where communities are endlessly in conflict against each other.

My point here is that both the stable countries and the dynamically changing communities just might be brought together in cooperation rather than be separated in conflict. Each region has its own diversified context, and each is different. Both the stable society and the turbulent society must respect the other. A new spatial model to act as an appropriate social solution for sustaining stability in these regions needs to be found. Through practical investigation into situations like Fukushima, I believe we could find a new vision for local communities and design a model to make the vision a reality.

Ihope that the vision of the Network Community can also be adapted to those historical regions where the communities are aging, isolated and relatively inactive.

We must have a new vision for regional communities, and we must prepare a model for that vision.

The signs of turbulence started in Japan; my country suffered the catastrophe of the destruction, by earthquake and tsunami, of a nuclear power plant. And, in the wider world today, the mature and stable Europe has started to experience tumult and unease from its encounter with chaotic Arabic countries, or with nations who are eager to achieve their own growth.

In other words, the world today cannot afford to have its countries split into two polarities.

A new social and spatial model is needed that will enable us to stand firm and safe between the two polarities of the regional model; we must try to make these two types of regions embrace each other in peace, both socially and spatially.

\section{References}

Satoh, S. (2014) 'Reforming the Network Community for Refugees Dispersed by the Fukushima Nuclear Power Plant Accident', City Planning 331, Japan City Planning Institute

Satoh, S. (1995) 'Joukamachi no kindai toshi zukuri [Castle-town Cities in Japan and Modern Urban Morphology]' (Tokyo, Kajima Institute Publishing).

Satoh, S. (1997) 'The Morphological Transformation of Japanese Castle-town Cities', Urban Morphology 1(1), 11-18.

Sugano, K., Okitsu, R. and Satoh, S. (2016) 'Medieval Castles and Pre-Modern Castle Towns Planned with Nature as the Heritage for Landscape Design Today: A Case Study of the Nanbu Region in Tohoku', History, Urbanism, Resilience: Planning and Heritage. International Planning History Society Proceedings 4, 274-284. 